\title{
Using caregivers' perceptions of rehabilitation services for children with Cerebral Palsy at public sector hospitals to identify the components of an appropriate service
}

\begin{abstract}
Despite a growing body of evidence favouring a familycentred approach to rehabilitation services for children with cerebral palsy $(C P)$, the essential components for a quality service for children with disabilities and their families living in poorly-resourced South African (SA) settings remains unknown. The study aimed to identify key components of an appropriate rehabilitation service which would meet the needs of children with $C P$ and their caregivers at SA public sector hospitals. This cross-sectional descriptive study used the modified Measure of Processes of Care (MPOC-20) questionnaire together with two open-ended questions with a convenience sample of caregivers attending therapy at CP Clinics in Gauteng and Limpopo hospitals. A total of 263 caregivers attending Cerebral Palsy clinics at 31 public sector hospitals in Gauteng and Limpopo were interviewed. Kind and caring attitudes, exercises or "training" for the child, and practical assistance (handling ideas and suggestions, assistive devices, food supplements, nappies, advice) were components of care most valued. The most frustration was caused by long queues waiting for files or at the pharmacy and being treated disrespectfully whilst providing caregivers with information and explanations regarding treatment choice were services that could be improved. Key components for an appropriate therapy service include caring and respectful attitudes, hands-on therapy, handling suggestions and practical assistance. Logistical and administrative procedures together with disrespectul and unhelpful attitudes negatively impact rehabilitation service delivery.
\end{abstract}

\section{KEY WORDS: CEREBRAL PALSY, CAREGIVERS, THERAPY SERVICE, MEASURE OF PROCESSES OF CARE (MPOC)}

\section{INTRODUCTION}

Cerebral palsy (CP) is the single biggest cause of childhood disability worldwide (Stanley et al 2000, Hagberg et al 1996). It is a lifelong condition, and the goal of a rehabilitation service is to help the child and family function in the most effective way possible (Milner et al 1996). The value of family-centred principles in guiding the delivery of paediatric rehabilitation services has been advocated in the literature for a number of years, but only recently have paediatric service providers been able to base their practices on the evidence for family-centred services (FCS) and not merely on recommendations (Dyke et al 2006). As King et al ( 2004 ; 1996) point out, listening to the views and experiences of the care- givers of children with $\mathrm{CP}$ is important in identifying the essential components of a rehabilitation service that is not only relevant and appropriate to local conditions but also meets the needs of parents in a particular community. Details about specific behaviours of providers can be used to target areas where improvement is warranted and can inform service providers on how best to meet parents' needs (King et al 2004).

Although this process has been followed in a number of countries and settings (Dyke et al 2006; Hartley et al 2005; King et al 2004; Goldbart and Mukherjee 2001; Brodin and Molosiwa 2000; Milner 1996), the views, experiences and perceptions of caregivers of children with $\mathrm{CP}$ attending therapy at public sector hospitals in South African have not been described. This makes it difficult for South African service providers in public hospitals to know whether the intervention services they are offering to children with $\mathrm{CP}$ and their caregivers are relevant and appropriate and whether they meet the needs of the caregivers and their families.

\section{Corresponding author:}

Gillian Saloojee

12a Rhodes Avenue,

Parktown,

Johannesburg

2193

South Africa

Email: gsaloojee@icon.co.za 
This study had a two-fold aim - firstly to identify the characteristics of the present services for children with $\mathrm{CP}$ most (and least) valued by caregivers living in poorly-resourced areas and secondly, to assess from the caregivers' perspective, what aspects of FCS service providers were currently doing well. Information from this study will assist in identifying the key components of an appropriate service for children with cerebral palsy attending public sector hospitals which will meet the needs of the children and their caregivers.

\section{METHOD}

This cross-sectional descriptive study used a convenience sample of caregivers of children aged between one and eighteen years with a diagnosis of cerebral palsy. The participants had to be living in poorly resourced periurban, urban or rural area and had to have received at least three months of rehabilitation therapy services (physiotherapy, occupational therapy and/or speech therapy) at a public sector hospital in Gauteng or Limpopo Province. Only district, secondary and tertiary hospitals with established services for children with cerebral palsy (i.e. a regular weekly or monthly cerebral palsy clinic) were eligible for inclusion in the study. This study formed part of a larger study (Saloojee et al 2009) and the sample size was based on Nunnally's (1978) suggested criterion of a minimum of 10 participants for each scale item. As one of the measuring instruments used in the current study had 22 items, a minimum sample size of 220 subjects was therefore considered appropriate. Caregivers were excluded from the study if their children had undergone surgery related to the $\mathrm{CP}$ condition in the previous six months.

Following approval by the Human Research Ethics Committee of the University of the Witwatersrand (Clearance Certificate R14/49) and the respective Departments of Health of Gauteng and Limpopo Provinces, data collection took place over a four month period (August to November) in 2004. All eligible caregivers were invited to participate in the study when they arrived at the hospital for their monthly therapy appointments. Two hundred and sixty three caregivers consented to take part in the study.

The Gross Motor Function Classification System (GMFCS) (Palisano et al 1997) was used to classify the child according to their functional motor abilities. This is a standardised method to describe the gross motor functional ability of children with $\mathrm{CP}$ in one of five ordered levels. Children at Level I can perform most or all the activities of their normally developing age-matched peers (although the speed and quality of movement may be limited), whereas children at Level V have difficulty controlling their head and trunk posture in most positions or achieving any voluntary control of movement. The child's age was also taken into account when determining the rating.

Apart from a general demographic questionnaire, two tools were used - the Measure of Processes of Care (MPOC) and a short questionnaire consisting of two open-ended questions. The Measure of Processes of Care (MPOC) was developed in Canada and it assesses caregivers' reported experiences of familycentred behaviours of rehabilitation service providers (King et al 2004). The measure is specifically intended for families of children with neurodevelopmental disorders and is designed to examine caregivers' care experience in its entirety rather than individual professional efforts. The MPOC is a self-report scale covering five target areas namely: enabling and partnership; providing general information; providing specific information; co-ordinated and comprehensive care; and respectful and supportive care. For each item, the caregiver responds to a common question "To what extent do the people who work with your child ..." followed by an item that begins with a verb describing service provider behaviour. Items are scored on a 1 (never) to 7 (to a great extent) basis.

For this study a modified version of the MPOC-20, the MPOC-SA (22) was used (Saloojee 2009). However, the total scores for each of the five subscales of this outcome measure could not be used to provide an overall rating of the parents' perceptions of familycentred care they received because the
MPOC-22(SA) as a whole has been shown to neither a reliable nor valid tool for this population. But as one of the aims of the study was to assess caregivers' perceptions of which particular aspects of FCS service providers were currently doing well, the responses to each individual item of the measure still provided useful information on the perceptions of individual elements of the quality of care they received. Therefore, for the purposes of this study, the MPOC seven point Likert scale was collapsed to a three point scale. Scores between one and three were considered "unfavourable responses"; a score of four was considered a neutral response whilst scores between five and seven were considered "favourable responses." The scores were not summed. This made it possible to identify the aspects of family-centred services caregivers perceived service providers to be doing well.

In addition to the interview-administered MPOC-SA(22), two-opened questions were included. Caregivers were asked to name (1) the three aspects they liked best and (2) the three aspects they liked the least about the service. The interviewers translated and recorded their responses in English. Two unemployed mothers of children with disabilities from Soweto were recruited via a community-based day care centre for children with multiple disabilities and trained as interviewers by the principal investigator. In addition to being fluent in English, they were able to read, speak and understand all six languages (Isizulu, Setswana, Sesotho, Sepedi, Xitsonga and Tshivenda) required for the study and were comfortable talking about their own children as well as talking to other mothers.

An Access database was used for data entry. The data were analysed using SPSS ${ }^{\circledR}$ (Version 13.0) for Windows statistical package (SPSS Inc, Chicago, USA). Descriptive statistics and frequency tables were the first step for data analysis. Responses to the two open-ended questions regarding the aspects of the service best and least liked were analysed using open coding and then grouped into similar categories as described by Neumann (2000). 


\section{RESULTS}

\section{Demographic characteristics of care- givers and children}

A total of 263 caregivers were interviewed: 127 (48.3\%) were from 13 hospi tals in Gauteng and $136(51.7 \%)$ were from 18 hospitals in Limpopo. Almost all caregivers (96\%) interviewed were either the child's mother $(87 \%)$ or grandmother $(9 \%)$. The majority of caregivers (179 [70\%]) were under the age of 35 years. Just over half $(58 \%)$ had completed primary school education and the majority $(78 \%)$ were unemployed. The majority of families (72\%) lived in formal housing whilst just over a quarter lived in informal shacks or mud huts. A government social assistance grant (equivalent to R780 at the time of the study) was the only source of income for a fifth of the families and the majority of families [226 (86\%)] had a monthly income of R1000 or less.

The mean age of the children was 3.3 years $(\mathrm{SD}=2.6)$. The majority of children (173 [66\%]) were classified as GMFCS Level IV and V, indicating severe functional disability whilst $48(18 \%)$ were moderately involved (GMFCS Level III) and the remaining 43 children $(16 \%)$ were GMFCS Level I and II, indicating milder functional disability. Almost two-thirds of the children $(\mathrm{n}=166$ [63\%]) had attended therapy for 12 months or longer.

\section{Most and least valued characteristics of current service delivery}

Regarding the two open-ended questions about aspects of the service most and least valued by caregivers, 224 caregivers provided a total of 542 responses to the first question, and 168 caregivers provided a total of 303 responses to the second question (Tables 1 and 2).

The therapists' caring attitudes towards the child and the caregiver together with the exercises or "training" the child received were the most common positive attributes of the service and accounted for $60 \%$ of the responses recorded (Table 1). A quarter of the responses included the following three characteristics - the role of the doctor at the $\mathrm{CP}$ Clinic in examining the children and treating caregivers with respect; the specific handling skills therapists showed the caregivers which enabled them to interact with and to handle their children more effectively; and the respect and affirmation therapists gave caregivers. A further $5 \%$ of responses specifically mentioned the practical assistance (in the form of assistance with transport costs, food supplements, nappies, toys and accessing care dependency grants) as another positive aspect of the current service.

Over $40 \%$ of the responses were complaints about the long queues at the dispensary waiting for medicine as well as inefficient administrative procedures and having to wait for files at the out patients department (Table 2). Disrespectful and "uncaring" attitudes of the staff (i.e. nurses, doctors and therapists) accounted for a further 30\% of the responses regarding characteristics least valued by caregivers whilst $6 \%$ of responses specifically mentioned disrespectful treatment and unhelpful attitudes from cleaners and clerks in the therapy departments. Caregivers also expressed dissatisfaction with the long waiting lists for therapy appointments (6\% of respondents) and cited a lack of equipment and assistive devices such as wheelchairs and buggies as aspects of current services least valued.

\section{Perceptions of Family-Centred Services (FCS)}

Caregivers' perceptions of family-centred behaviours they thought therapists were doing well were that therapists talked to the caregivers and explained what they doing during therapy; they made caregivers feel that as parents, they were doing a good job; they provided a caring atmosphere; caregivers felt that they gained something from every session and were given suggestions and ideas or things to do at home between visits to the hospital (Table 3).

Family-centred behaviours which caregivers perceived in an unfavourable light were insufficient opportunities for

Table 1: Number of responses relating to what caregivers liked best about the service $(n=542)$

\begin{tabular}{|l|l|l|}
\hline Response & $\mathbf{n}$ & \% \\
\hline Therapists' caring attitude to child and caregiver and good communication with caregivers & 168 & 31.0 \\
\hline Good therapy service (i.e. the exercises or “training” the children receive) & 159 & 29.3 \\
\hline Doctors role ( examining the children; good communication with mothers and caring attitude) & 61 & 11.2 \\
\hline Caregiver taught specific skills handling and interacting with the child & 47 & 8.7 \\
\hline Caregiver affirmed and made to feel good about herself; felt respected & 35 & 6.4 \\
\hline Assistance with grants, schools, transport costs, food and food supplements, nappies, toys, equipment & 25 & 4.6 \\
\hline Therapists' punctuality; short waiting time for treatment) & 11 & 2.0 \\
\hline Hospital environment (neat, clerks good) & 10 \\
\hline Children receive good medication & 1.8 \\
\hline Centralised service for children (“all in one place'), services free & 13 & 2.4 \\
\hline Friendly nurses: assistance with interpretation & 6 & 1.1 \\
\hline TOTAL NUMBER OF"BEST LIKED ASPECTS" GIVEN BY CAREGIVERS & 7 & 1.3 \\
\hline
\end{tabular}


Table 2: Number of responses to what caregivers liked least about the service $(n=303)$

\begin{tabular}{|c|c|c|}
\hline Response & $\mathbf{n}$ & $\%$ \\
\hline Dispensary: long queues to get medicine & 61 & 20.1 \\
\hline Clerks and OPD: waiting times for files; rude clerks; inefficient service & 62 & 20.5 \\
\hline $\begin{array}{l}\text { Therapists: uncaring; in a hurry; poor explanations; arrive late; don't speak the language; lazy; } \\
\text { poor treatment; no follow-up appointment; poor communication with parents }\end{array}$ & 40 & 13.2 \\
\hline $\begin{array}{l}\text { Doctors attitudes: uncaring; impatient; see children infrequently; poor explanation of results } \\
\text { and medications }\end{array}$ & 28 & 9.2 \\
\hline Nurses' attitudes: rude, harsh, uncaring & 28 & 9.2 \\
\hline Waiting time for therapy & 18 & 5.9 \\
\hline Lack of therapy equipment and wheelchairs & 17 & 5.6 \\
\hline Being treated disrespectfully by cleaners, clerks in therapy department; general unhelpfulness & 16 & 5.2 \\
\hline Distance and transport to the hospital & 9 & 3.0 \\
\hline No home visits; therapy too infrequent & 8 & 2.6 \\
\hline OPD - long queue to see doctor, even when child sick & 8 & 2.6 \\
\hline Not enough doctors and therapists & 5 & 1.6 \\
\hline Bureaucracy - being shunted from pillar to post & 3 & 1.0 \\
\hline TOTAL NUMBER OF “LEAST LIKED ASPECTS” GIVEN BY CAREGIVERS & 303 & 100.0 \\
\hline
\end{tabular}

the whole family to obtain information; insufficient advice on how to get information or contact other parents; caregivers did not feel that they were given opportunities to make decisions about treatment; and that treatment choices were not explained to them (Table 3 ).

\section{DISCUSSION}

Caregivers in this study generally expressed satisfaction with current services and felt that they gained something from coming for therapy. This is not surprising given that the sample population was caregivers who attended therapy regularly. This is a limitation of the study as it does not reflect the views of those caregivers who no longer come for therapy. Their views are relevant as the reasons why they stopped attending may be related to negative aspects of, or dissatisfaction with, the service. As the sample was drawn from 31 of the 36 eligible hospitals in Gauteng and Limpopo, a wide and presumably geographically representative spread is reflected. As the responses to the questions have been combined, it is not possible to make comparisons between hospitals or between provinces. The aim of the study was to obtain the overall perceptions of caregivers attending therapy services at public sector hospitals, rather than to compare hospitals or provinces.

Both measuring tools described the same two traits most valued by caregivers - the kind and caring attitudes of the therapists ("They show love to my child") and the exercises or "training" the child received ("They give my child good treatment"). Caregivers also valued being taught specific handling skills; and being respected and affirmed as parents. Practical assistance in the form of the provision of assistive devices, food supplements and nappies together with advice regarding finding schools and accessing welfare grants was also appreciated. This echoes the findings of Hartley's (2005) study in Uganda where parents expressed the need for assistive devices, physical resources such as food and money, and access to education for their children.

Weaknesses of the current services identified by the caregivers in the current study included the long queues at the dispensary and the out-patient departments; disrespectful and uncaring attitudes of all staff (i.e. therapists, nurses, doctors, cleaners and clerks) as well as limited explanations given regarding treatment choices and providing information about their child's disability and available services. The dissatisfaction with the limited explanations regarding treatment choices may be explained by the fact that in public sector hospitals in poorly-resourced, treatment choices are limited in the first place.

Caregivers' need for further information has been highlighted in studies in various settings - from Botswana (Brodin and Molosiwa 2000) and Uganda (Hartley et al 2005) to the United Kingdom (Milner et al 1996), and Australia (Dyke et al 2006) and suggest that this is a universal need and one which therapy services do not always adequately address.

As Dyke et al (2006) point out, the provision of information empowers families to make decisions about their children and alleviates the stress arising from ignorance. However, it needs to be recognized that poorly-resourced settings are characterized by a lack of support services, schools and treatment choices and this may also have contributed to the fact items relating to the provision of information received unfavourable scores.

Waiting times at the dispensary, the out-patient department for therapy as well as being treated disrespectfully were the main criticisms of current 
Table 3: Caregiver's responses to the MPOC items (number of respondents, $\mathbf{n}=\mathbf{2 6 0}$ )

\begin{tabular}{|c|c|c|c|c|}
\hline $\begin{array}{l}\text { MPOC ITEM: To what extent do the people who work } \\
\text { with you and your child.... }\end{array}$ & N/A & $\begin{array}{l}\text { UNFAVOURABLE } \\
\text { rating of } 1,2 \text { or } 3\end{array}$ & $\begin{array}{l}\text { NEUTRAL } \\
\text { Rating of } 4\end{array}$ & $\begin{array}{l}\text { FAVOURABLE } \\
\text { Rating or } 5,6 \text { or } 7\end{array}$ \\
\hline Explain what they are doing during therapy & 0 & 5 & 6 & 249 \\
\hline Make you feel as a parent you are doing a good job & 0 & 4 & 12 & 244 \\
\hline $\begin{array}{l}\text { To what extent are you satisfied with the therapy service } \\
\text { you receive here }\end{array}$ & 0 & 13 & 12 & 235 \\
\hline $\begin{array}{l}\text { To what extent do you feel you gain something from } \\
\text { every session }\end{array}$ & 0 & 15 & 11 & 234 \\
\hline Talk to you and tell what they are doing & 0 & 13 & 14 & 233 \\
\hline $\begin{array}{l}\text { Provide a caring atmosphere rather than just give } \\
\text { you information }\end{array}$ & 0 & 10 & 20 & 230 \\
\hline Give you suggestions and ideas of things to do at home & 3 & 16 & 14 & 227 \\
\hline Explain what they want you to do between visits & 1 & 22 & 12 & 225 \\
\hline $\begin{array}{l}\text { Treat you as an equal rather than just a parent } \\
\text { of a patient }\end{array}$ & 1 & 20 & 20 & 219 \\
\hline Provide enough time to talk so you don't feel rushed & 2 & 15 & 25 & 218 \\
\hline $\begin{array}{l}\text { Treat you as an individual rather than as a } \\
\text { "typical parent" }\end{array}$ & 0 & 23 & 26 & 211 \\
\hline $\begin{array}{l}\text { Ensure you had a chance to explain the concerns and } \\
\text { things that worry you most }\end{array}$ & 6 & 30 & 20 & 204 \\
\hline $\begin{array}{l}\text { Give you information about your child that is consistent } \\
\text { from one person to the next }\end{array}$ & 4 & 32 & 25 & 199 \\
\hline Follow-up on things you discussed or wanted to know & 8 & 29 & 31 & 192 \\
\hline Look at the needs of your whole child & 1 & 43 & 29 & 187 \\
\hline $\begin{array}{l}\text { Provide information about the types of services offered } \\
\text { at the hospital }\end{array}$ & 3 & 62 & 23 & 172 \\
\hline Explain and tell you about results from assessments & 27 & 55 & 16 & 162 \\
\hline $\begin{array}{l}\text { Make sure that at least one member of the team is } \\
\text { someone who works with you over a long period of time }\end{array}$ & 3 & 54 & 44 & 159 \\
\hline Have information available in various forms & 3 & 68 & 31 & 158 \\
\hline Have information available about your child's disability & 0 & 43 & 22 & 122 \\
\hline $\begin{array}{l}\text { Provide advice on how to get information or } \\
\text { how to contact other parents }\end{array}$ & 7 & 114 & 18 & 121 \\
\hline $\begin{array}{l}\text { Give you the opportunity to make decisions } \\
\text { about treatment }\end{array}$ & 9 & 121 & 14 & 116 \\
\hline Fully explain treatment choices to you & 63 & 78 & 12 & 107 \\
\hline $\begin{array}{l}\text { Provide opportunities for the whole family to obtain } \\
\text { information }\end{array}$ & 7 & 155 & 19 & 79 \\
\hline
\end{tabular}

rehabilitation services. Aside from the disrespectful attitudes, these aspects are challenging to change as they require shifts in policies and procedures at a level beyond which therapists currently have much influence.

The findings of this study and similar research conducted in Australia (Dyke et al 2006) highlights the differences between well-resourced and poorlyresourced settings with regard to caregiver perceptions of the components contributing to good service provision. Caregivers in Australia expressed the need for more general support for the whole family through exploring their feelings for having a child with special needs; helping them to feel more com- petent as parents; and tailoring treatment plans to the different lifestyles of families, while caregivers in South Africa expressed a greater need for being treated with respect and for practical support in the form of handling ideas, assistive devices, physical resources (food and transport) and access to schools rather than support for the whole family. 
In planning a more effective therapy service in a public service setting, the suggestions emanating from this study confirm what Groce (1999) has already noted - that in poor settings, rehabilitation professionals need to do more than simply deliver technical services in a clinical setting. In these areas the need for rehabilitation rarely exists in isolation from social needs. Thus the message to therapists concerns the necessity of having a broader outlook when planning and delivering a service for children with cerebral palsy. It is not sufficient to focus only on technical expertise within a family-centred framework. Environmental factors, particularly the lack of resources such as schools, assistive devices and transport are equally important and need to be addressed. Advocacy for improved access to assistive devices and schooling for children with special needs is also recommended.

\section{CONCLUSION AND RECOMMENDATIONS}

The key components identified by this study for an appropriate therapy service for children with cerebral palsy at a South African public service hospital include:

- Kind, caring, helpful and respectful attitudes from all staff

- "Hands-on therapy" (or in the words of the caregivers "training and exercises")

- Talking to caregivers and providing explanations on what is happening during therapy

- Teaching caregivers specific handling skills and giving suggestions on the day to day management and caring for the children (e.g., how to feed the child; ideas for playing with the child; how to "loosen stiff muscles"; how to help the child to sit, etc)

- Practical help with obtaining assistive devices, nappies, schools, child dependency grants, etc.

- Information regarding their child's disability together with information about available services and support structures

In public sector hospitals, therapy services do not exist in isolation. Logistical issues and administrative procedures can impact negatively on rehabilitation services when caregivers spend many hours in queues waiting for files or for medication and these aspects are often beyond the scope and control of therapists.

\section{Acknowledgements}

Prof. M. Westaway assisted with the data analysis and we thank her for the expertise. We wish to thank the caregivers and rehabilitation professionals who participated in this study for sharing their time and experiences. We gratefully acknowledge Sonto Nhlabathi and Grace Phiri, the two field workers who conducted all the interviews. Financial support was provided by the South African Medical Research Council, the South African Society of Physiotherapy, the University of the Witwatersrand and the British Association of Bobath Trained Therapists.

\section{REFERENCES}

Brodin J, Molosiwa S 2000 Support for families with children with mental retardation in Botswana. Southern Africa International Journal of Rehabilitation Research 23: 163 - 167

Dyke P, Buttigieg P, Blackmore AM, Ghose A 2006 Use of the Measure of Processes of Care for families (MPOC-56) and service providers (MPOC-SP) to evaluate family-centred services in a paediatric disability setting. Child: Care, Health and Development 32(2): 167-176

Goldbart J, Mukherjee S 2001 A comparative evaluation of two models of service delivery for families with a child with cerebral palsy. International Journal of Rehabilitation Research 24: $325-328$

Groce NE 1999 Health beliefs and behaviour towards individuals with disability cross-culturally. In: Leavitt R, editor. Cross-cultural rehabilitation. An international perspective. London. W.B. Saunders

Hagberg B, Hagberg G, Olow, Von Wendt L 1996 The changing panorama of cerebral palsy in Sweden. VII: Prevalence and origin in the birth year period 1985-1990. Acta Pediatrica Scandinavica 85: 954-60

Hartley S, Ojwang P, Baguwemu A, Ddamulira M, Chavuta A 2005 How do carers of disabled chil- dren cope? The Ugandan perspective. Child: Care, Health and Development 31: 167 - 180

King S, Rosenbaum P, King G 1996 Parents' perceptions of caregiving: development and validation of a measure of processes. Developmental Medicine and Child Neurology 38: 757 - 772

King S, King G, Rosenbaum P 2004 Evaluating health service delivery to children with chronic conditions and their families: Development of a refined Measure of Processes of Care (MPOC-20). Children's Health Care 33(1): 35-57

Milner J, Bungay C, Jellinek D, Hall DMB 1996 Needs of disabled children and their families. Archives of Disability in Childhood 75: 399-404

Neumann WL 2000 Social Research Methods. Qualitative and quantitative approaches. Fourth edition. Boston: Allan and Bacon

Nunnally JC 1978 Psychometric theory. Second edition. New York: McGraw-Hill

Palisano R, Rosenbaum P, Walter S, Russell D, Wood E, Galuppi B 1997 Development and reliability of a system to classify gross motor function in children with cerebral palsy. Developmental Medicine and Child Neurology 39: 214 - 223

Stanley F, Blair E, Alberman E 2000 How common are the cerebral palsies? In: Cerebral Palsies: Epidemiological and Causal Pathways Clinic in Developmental Medicine No. 151. pp 22-39. London:Mac Keith Press.

Saloojee G, Rosenbaum PR, Westaway MW, Stewart AV 2009 Development of a measure of family-centred care for resource poor South African settings: the experience of using a modified version of the MPOC-20. Child: Care, Health and Development 35 (1): 25-32 